\title{
Undoped SiGe material calibration for numerical nanosecond laser annealing simulations
}

\author{
A-S. Royet \\ CEA-LETI, MINATEC \\ Campus \\ Université Grenoble Alpes \\ Grenoble, France \\ anne-sophie.royet@cea.fr
}

\author{
L. Dagault \\ CEA-LETI, MINATEC \\ Campus \\ Université Grenoble Alpes \\ Grenoble, France \\ sebastien.kerdiles@cea.fr
}

\author{
S. Kerdilès \\ CEA-LETI, MINATEC \\ Campus \\ Université Grenoble Alpes \\ Grenoble, France \\ sebastien.kerdiles@cea.fr
}

\author{
P. Acosta Alba \\ CEA-LETI, MINATEC \\ Campus \\ Université Grenoble Alpes \\ Grenoble, France \\ pablo.acostaalba@cea.fr
}

\author{
K. Huet \\ LASSE \\ SCREEN SPE \\ Gennevilliers, France \\ karim.huet@screen-lasse.com
}

\begin{abstract}
Physical parameters calibration (dielectric and alloy properties) of $\mathrm{Si}_{1-x} \mathrm{Ge}_{\mathrm{x}}$ alloys is presented in order to simulate the Ultra Violet-Nanosecond Laser Annealing (UVNLA) of this material for $\mathrm{Si} / \mathrm{Si}_{1-\mathrm{xGex}}$ based MOS devices. Optical and physical parameters are extracted and modeled from experimental characterizations for several Ge concentrations and then fitted to match experimental laser annealing results. A good prediction, in terms of melt depth and melting duration, is achieved for different Ge concentrations between 20 and $40 \%$, usually encountered in $\mathrm{Si}_{1-x} \mathrm{Gex}$ CMOS integration process.
\end{abstract}

Keywords- Laser annealing, melt depth, SiGe alloy characterization.

\section{INTRODUCTION}

Strained SiGe epi-layers are very interesting for MOSFET technology thanks to their higher mobility compared to $\mathrm{Si}$ as well as interesting optical properties [1-2]. However, strain relaxation and defect formation may occur during the growth process and the strain is difficult to maintain especially for high Ge concentrations. In addition, UV-NLA is a very promising technique for $3 \mathrm{D}$ sequential integration due to the combination of a very short pulse duration (hundred of nanoseconds) and the limited UV light penetration in most of semiconductors used for CMOS integration [3-4]. These unique conditions make UV-NLA a good candidate for suppressing the propagation and growth of defects like dislocations. Laser Annealing of $\mathrm{Si}_{1-\mathrm{X}} \mathrm{Ge}_{\mathrm{X}}$ layers has been investigated for several years and has demonstrated many benefits such as a high electrical activation efficiency and a low contact resistance due to the formation of a Ge-rich layer during UV-NLA [5-7]. In this context, UV-NLA numerical simulation is a powerful tool to predict thermal budget in the structure and the process window in terms of laser beam energy density $\left(\mathrm{ED}, \mathrm{J} / \mathrm{cm}^{2}\right)$. However, in order to obtain an accurate prediction, such numerical tool needs a calibrated material properties database as well. In addition to the thermal properties, the main material parameters concerned are optical (permittivity variations with temperature and $\mathrm{Ge}$ concentration) and alloy parameters (segregation coefficient). This work shows numerical simulations combined with a large number of experimental data used to calibrate $\mathrm{SiGe}$ material behavior upon UV-NLA. It is also shown that once the material is calibrated, the simulations are able to accurately describe molten material thicknesses, Ge concentration distributions and laser annealing kinetics.

\section{SimULATION TOOL AND EXPERIMENTAL DESCRIPTION AND STRATEGY}

Numerical simulations were performed using LIAB simulation software described in [8]. This tool solves selfconsistently the heat equation coupled to the time harmonic solution of Maxwell equation (UV laser light coupling), including temperature dependency of materials parameters and phase change (here using a phase field based approach [9]).

The experimental procedure is based on the stack, illustrated in Fig.1, consisting in a pseudomorphic 30 to $35 \mathrm{~nm}$-thick undoped $\mathrm{Si}_{1-\mathrm{X}} \mathrm{Ge}_{\mathrm{X}}$ layer with $\mathrm{Ge}$ concentrations from 0 up to $40 \%$. Those layers were deposited on n-type $\mathrm{Si}$ (100) substrates using experimental conditions as described in [6]. Such $\mathrm{Si}_{1-\mathrm{x}} \mathrm{Ge}_{\mathrm{X}}$ layers have been widely characterized: optically by spectroscopic ellipsometry and physically thanks to a Secondary Ion Mass Spectrometry (SIMS) system.

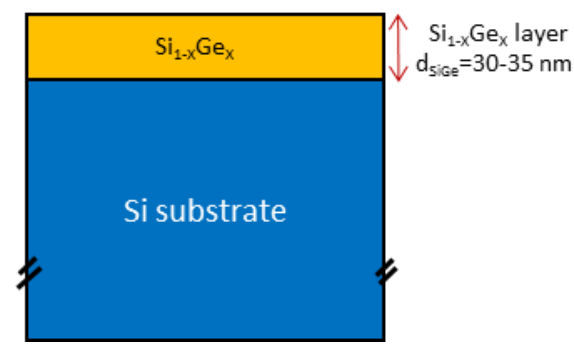

Fig. 1: Experimental stack used for $\mathrm{Si}_{1-\mathrm{X}} \mathrm{Ge}_{\mathrm{X}}$ parameters calibration.

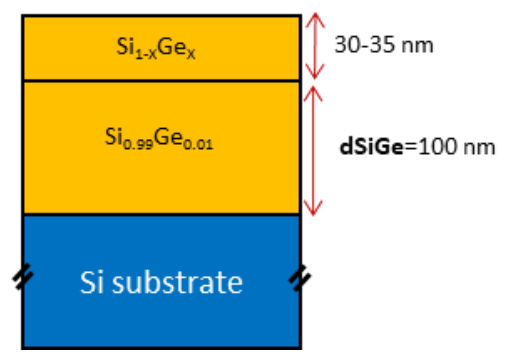

Fig. 2: Corresponding modeling for 1D numerical simulations with LIAB tool. 


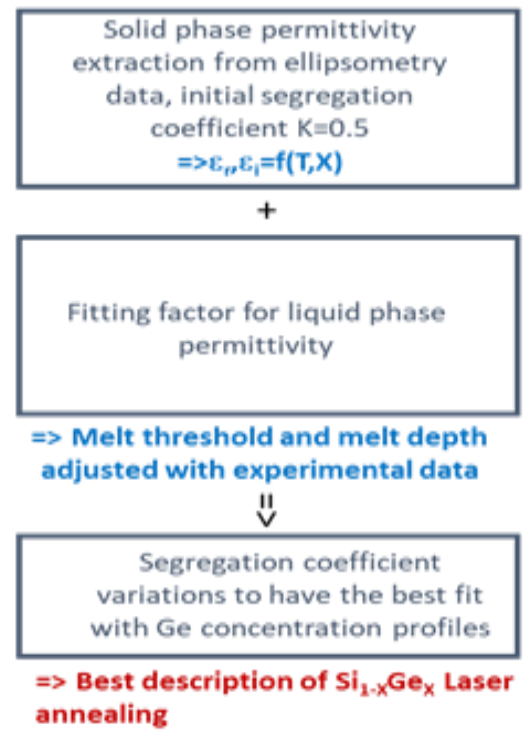

Fig. 3: Simulation strategy for $\mathrm{Si}_{1-\mathrm{X}} \mathrm{Ge}_{\mathrm{X}}$ parameters calibration.

The samples were submitted to pulsed laser annealing in a SCREEN-LT3100 system based on a $\mathrm{XeCl}$ excimer laser (308 $\mathrm{nm}$ wavelength and $145 \mathrm{~ns}$ pulse duration) at various ED. The resulting composition of $\mathrm{Si}_{1-\mathrm{X}} \mathrm{Ge}_{\mathrm{X}}$ layers has been extracted from (SIMS) measurements detailed elsewhere [68].

1D numerical simulations were carried out using the stack shown in Fig. 2 where the layer $\mathrm{Si}_{0.99} \mathrm{Ge}_{0.01}$ was introduced to take into account Ge diffusion into the Si substrate. These simulations were performed at various ED ranging from 1.2 to $2.4 \mathrm{~J} / \mathrm{cm}^{2}$. We followed the calibration methodology summarized in Fig.3. The first step is to calculate permittivity values in the solid phase from the experimental data and which can account for the real reflectivity and absorption in the material. After that, the liquid phase permittivity values will be calibrated in order to fit the experimental molten thickness and melting threshold values. Finally, the segregation coefficient can be adjusted to find germanium concentration profiles close to those given by the experimental measurements.

Table I: Description of material characteristics used in the LIAB database for numerical simulations and $\mathrm{Si}_{1-\mathrm{X}} \mathrm{Ge}_{\mathrm{X}}$ calibration. $\varepsilon_{\mathrm{r}}$ and $\varepsilon_{\mathrm{i}}$ are real and imaginary permittivity in solid phase respectively. $\varepsilon_{\mathrm{Lr}}, \varepsilon_{\mathrm{Li}}$ are real and imaginary permittivity in liquid phase.

\begin{tabular}{|c|c|c|c|}
\hline Material & $\begin{array}{l}\text { Permittivity in solid } \\
\text { phase }\end{array}$ & $\begin{array}{l}\text { Permittivity in } \\
\text { liquid phase }\end{array}$ & $\begin{array}{l}\text { Segregation } \\
\text { coefficient K }\end{array}$ \\
\hline REF & $\begin{array}{c}\varepsilon_{r}, \varepsilon_{i}=f(T, X) \text { with a simple } \mathrm{Si} \\
\text { and Ge parameter } \\
\text { linearization }\end{array}$ & \multirow[t]{2}{*}{$\varepsilon_{\mathrm{Lr}} \varepsilon_{\mathrm{Li}}=\mathrm{A}^{*}(1-\mathrm{X})-\mathrm{B}^{*} \mathrm{X}$} & \multirow{3}{*}{0.5} \\
\hline 1 & $\begin{array}{c}\varepsilon_{r}, \varepsilon_{i}=f(T, X) \text { with a } \\
\text { independent constants } \\
\text { between } 20 \text { and } 40 \%\end{array}$ & & \\
\hline & & \multirow[t]{2}{*}{$\begin{array}{c}\varepsilon_{\mathrm{Lr},} \varepsilon_{\mathrm{Li}}=\left[\mathrm{A}^{*}(1-\mathrm{X})-\right. \\
\left.\mathrm{B}^{*} \mathrm{X}\right]^{*} \mathrm{fC}\end{array}$} & \\
\hline Calibrated & & & 0.45 \\
\hline
\end{tabular}

\section{PARAMETERS CALIBRATION WITH GE CONCENTRATION AND TEMPERATURE}

The optical parameters of $\mathrm{Si}_{1-\mathrm{X}} \mathrm{Ge}_{\mathrm{X}}$ are not always well known and are often derived from the linearization of $\mathrm{Si}$ and Ge parameters from [10], considered here as the reference material, called REF, as indicated in Table I. In a first approach, we used ellipsometry measurements for different Ge concentrations, ranging from 10 to $40 \%$ and temperatures from $25^{\circ} \mathrm{C}$ up to $600^{\circ} \mathrm{C}$. The refractive index and the absorption coefficient were used to calculate real and imaginary part of the permittivity, $\varepsilon_{\mathrm{r}}$ and $\varepsilon_{\mathrm{I}}$ respectively. These values were fitted with polynomial functions depending on the temperature and the Ge content X. Fig.4 shows the permittivity values as a function of the temperature for various Ge contents and the corresponding fits. After that, a single polynomial function is deduced for $\varepsilon_{\mathrm{r}}$ and $\varepsilon_{\mathrm{I}}$ as indicated in eq.(1):

$$
\varepsilon_{\mathrm{r}}, \varepsilon_{\mathrm{i}}=\mathrm{A}(\mathrm{T}-300)+\mathrm{B}_{\mathrm{n}} \mathrm{X}^{\mathrm{n}}+\ldots \mathrm{B}_{1} \mathrm{X}+\mathrm{B}_{0}
$$

where $\mathrm{A}, \mathrm{B}_{0}, \ldots \mathrm{B}_{\mathrm{n}}$ are independent constants. This function is given as an input into the LIAB material properties database.

For the REF material, the variations of the liquid phase permittivity as a function of the Ge content, $\mathrm{X}$, are taken into account by linearization while the segregation coefficient is fixed at the value $\mathrm{k}=0.5$. Material 1 , also described in Table I, takes into account the permittivity variation in the solid phase with no variations on the segregation coefficient while material 2 takes into account both in the liquid and solid phase variations. Finally, the segregation coefficient is slightly tuned in order to better fit segregation profiles. Fig.5 shows the experimental and simulated melt thicknesses versus $\mathrm{ED}$ in the cases of $\mathrm{Si}_{0.80} \mathrm{Ge}_{0.20}$ and $\mathrm{Si}_{0.60} \mathrm{Ge}_{0.40}$. After several iterations with the different materials tested on the simulation database, a set of optimal parameters values is chosen in order to best fit experimental data thus resulting in a well calibrated $\mathrm{Si}_{1-\mathrm{X}} \mathrm{Ge}_{\mathrm{X}}$ material.

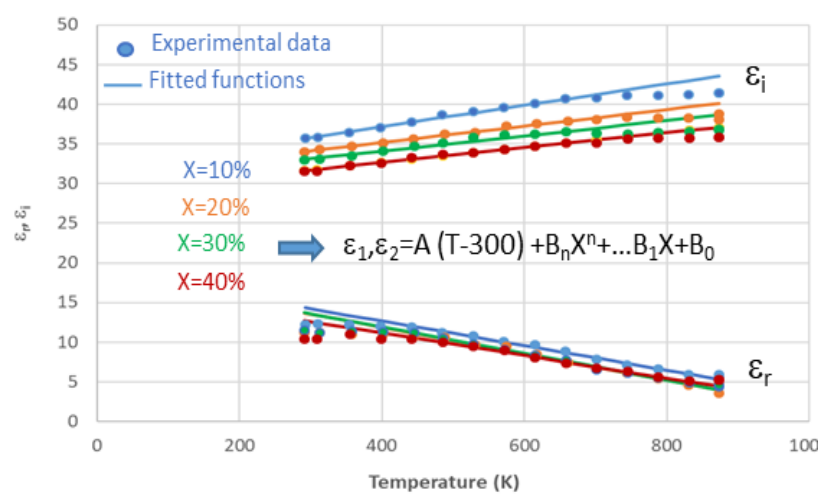

Fig. 4: Experimental permittivity variations (symbols) and fits (lines) versus temperature and $\mathrm{Ge}$ concentration. The polynomial function extracted from these results is given on the graph. All the constants $\mathrm{A}, \mathrm{B}_{0}$, $\ldots \mathrm{B}_{\mathrm{n}}$, are $\mathrm{T}$ and $\mathrm{X}$-independent. 

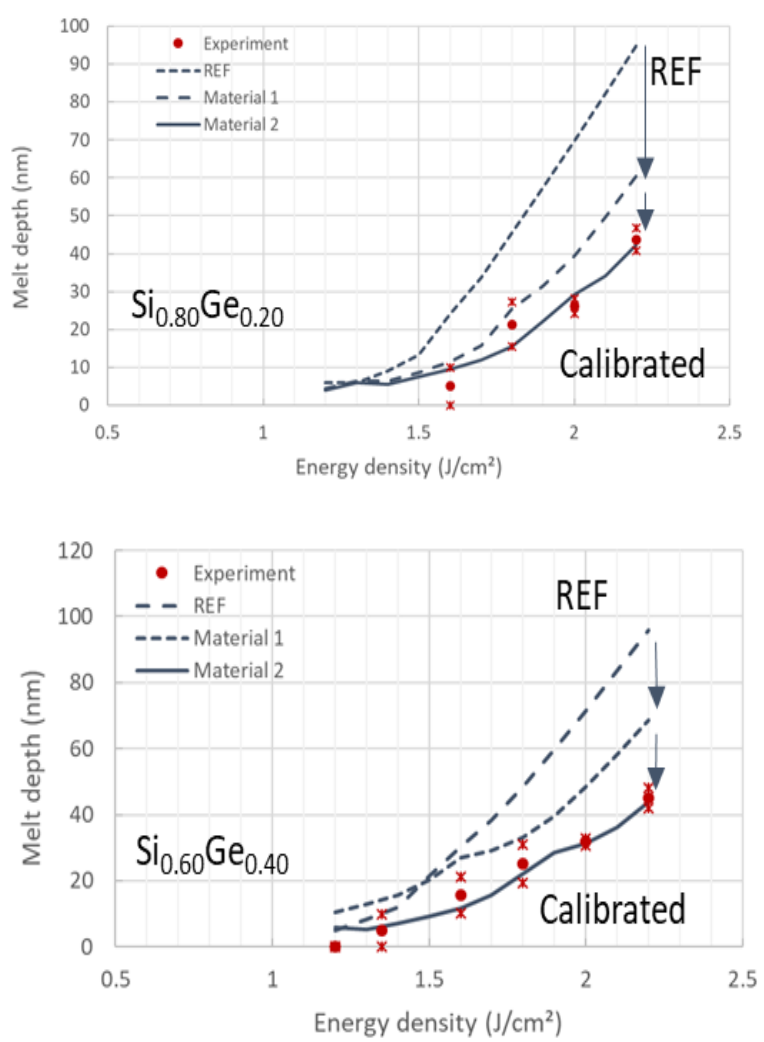

Fig. 5: Comparison of experimental melt depth (nm) and LTA simulation results for $\mathrm{Si}_{0.80} \mathrm{Ge}_{0.20}$ and $\mathrm{Si}_{0.60} \mathrm{Ge}_{0.40}$ as a function of the laser energy density. For $\mathrm{Si}_{080} \mathrm{Ge}_{020}$, the experimental point at $1.6 \mathrm{~J} / \mathrm{cm}^{2}$ can not be accurately measured. The molten thickness at this point strongly depends on the surface roughness and is evaluated at the average $5 \mathrm{~nm}$.

\section{ALLOYS PROFILES AND LA KINETICS ASPECTS}

Among the set of parameters, the segregation coefficient $\mathrm{k}=0.45$ is found to provide the best fit with Ge concentration depth profiles at various ED. In Fig.6, the experimental (full lines and points) and simulated (dotted lines) profiles are shown for $\mathrm{Si}_{0.80} \mathrm{Ge}_{0.20}$ and $\mathrm{Si}_{0.60} \mathrm{Ge}_{0.40}$ and for $\mathrm{ED}$ around 1.8, 2.0 , and $2.2 \mathrm{~J} / \mathrm{cm}^{2}$. Profiles are well described by the simulations in terms of melt depths and Ge contents at the surface especially at high ED ( $\left.>1.8 \mathrm{~J} / \mathrm{cm}^{2}\right)$.

In order to investigate kinetics aspects, the melting duration is extracted from experimental and simulated data. Fig.7 shows the laser annealing melting duration versus the melt depth. Even if the fit is not yet perfect, the calibrated simulations enable an acceptable estimation of the annealed material kinetic behavior for each $\mathrm{Ge}$ concentration. For example, at high $\mathrm{Ge}$ concentration ( $>20 \%$ ), it is experimentally observed that the melt duration decreases when the full melt of the SiGe layer is reached, which is well reproduced by the simulation. This decrease is attributed to the solidification rate variation when the $\mathrm{Si}$ substrate begins to melt. Figure 8 shows the simulated melt depth as a function of time for various ED values. For the highest ED, leading to the full SiGe layer melt, the solidification rate is found almost constant. In contrast, for lower ED values, leading to maximum melt depth within $\mathrm{SiGe}$ layer, the solidification exhibits a different behavior with 2 slopes. From maximum melt depth down to $\sim 10 \mathrm{~nm}$, the solidification rate is slightly lower than that obtained in the full melt conditions. Below $10 \mathrm{~nm}$ melt depth, the solidification rate decreases further, likely related to the high Ge concentration in the near surface region. This kinetic aspect can be taken into account by simulation with the calibrated material.
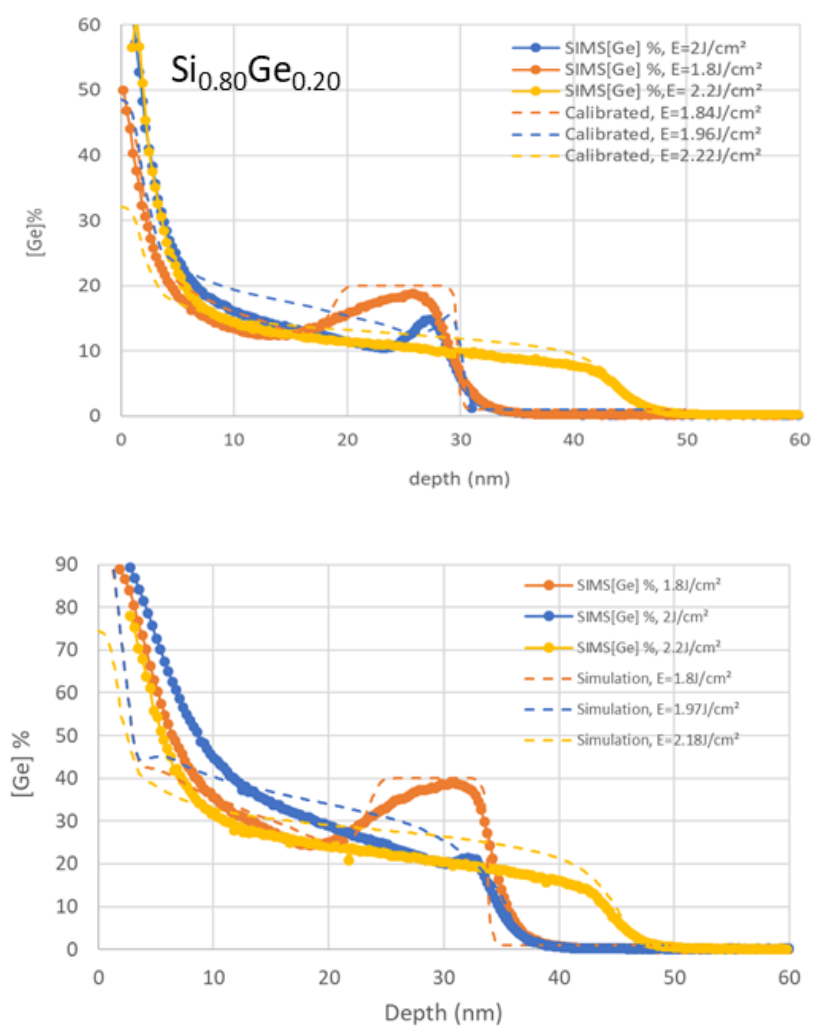

Fig. 6:: Experimental and simulated concentration depth profiles in $\mathrm{Si}_{0.80} \mathrm{Ge}_{0.20}$ and $\mathrm{Si}_{0.60} \mathrm{Ge}_{0.40}$ samples annealed at laser energy density from 1.8 to $2.2 \mathrm{~J} / \mathrm{cm}^{2}$.
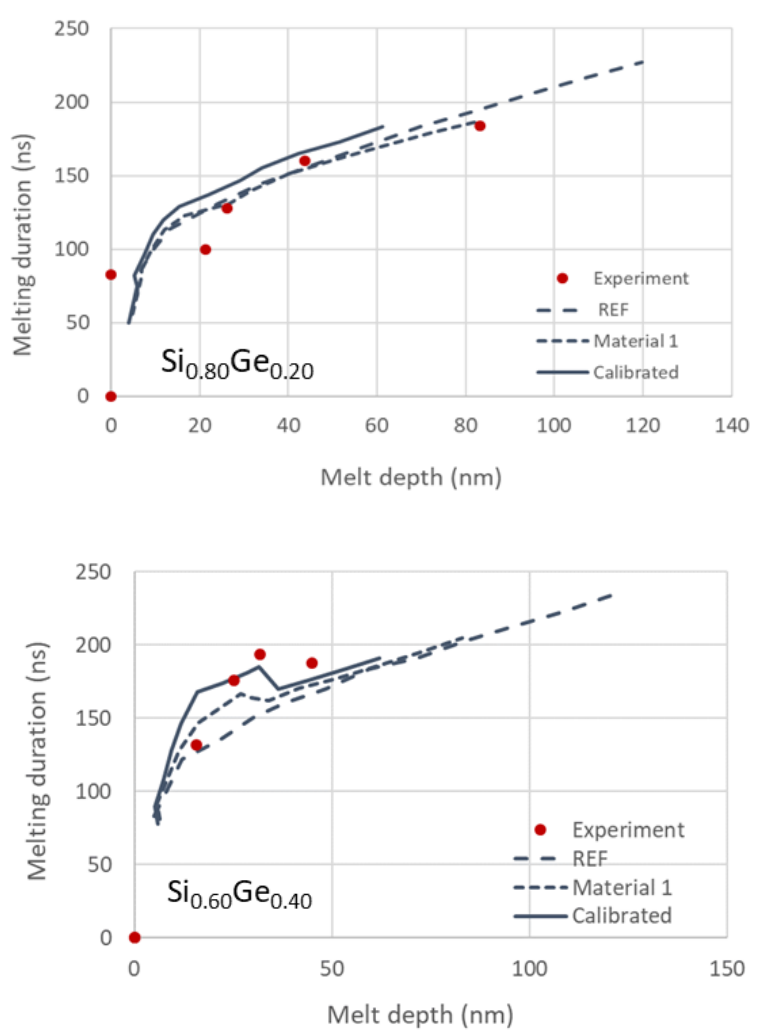

Fig. 7: Experimental and simulated melting duration (ns) as a function of melt depth (nm) for $\mathrm{X}=20$ and $40 \%$. 


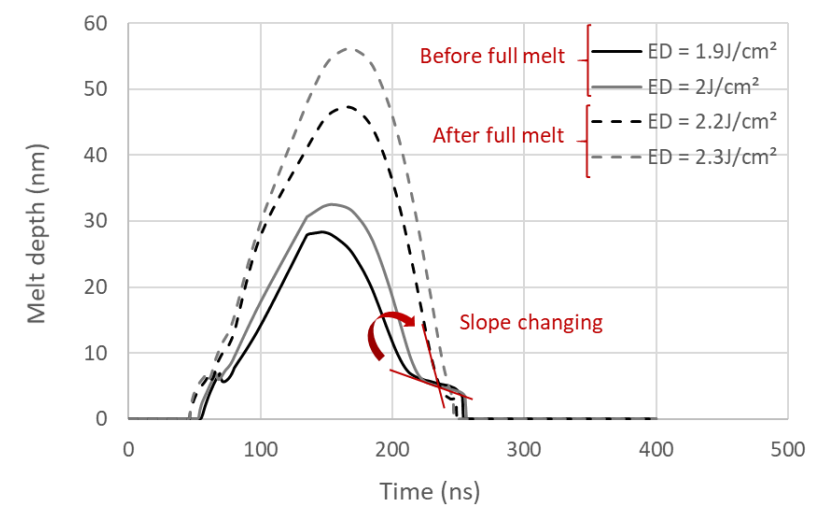

Fig. 8: Simulated melt depth (nm) as a function of time (ns). The slope variation at the end of the process represents the solidification rate variation after the full melt.

\section{CONCLUSION}

In this paper, we performed 1D numerical nanosecond laser annealing simulations of $\mathrm{Si}_{1-\mathrm{X}} \mathrm{Ge}_{\mathrm{X}}$ layers on $\mathrm{Si}$ substrate in order to calibrate this material by comparing simulation results with experimental measurements such as melt depth and duration of the material and Ge content segregation profiles. To have the best material calibration as possible, $\mathrm{Si}_{1-}$ ${ }_{x} \mathrm{Ge}_{\mathrm{x}}$ optical data measured from $25^{\circ} \mathrm{C}$ up to $600^{\circ} \mathrm{C}$ are fitted to obtained a polynomial function describing the permittivity variations with temperature in solid phase. Afterward, this function is introduced in the simulation tool database. The permittivity in liquid phase is also described by a linear $\mathrm{X}$ dependent equation and a correcting factor. The segregation coefficient in the material database is then finely tuned to have the best fit with experimental Ge segregation profiles for various $\mathrm{Ge}$ contents between 20 and $40 \%$. Kinetics aspects, such as melting duration are also investigated thanks to simulation results. The Ge concentration range of validity of these simulations is considered to be between 20 and $40 \%$.
Below $20 \%$, the dielectric permittivity loses in linearity. This concentration range practically corresponds to the needs of many applications.

\section{REFERENCES}

[1] G.E. Jellison, T.E Haynes, "Optical functions of silicon-germanium alloys determined using spectroscopic ellipsometry", Optical Materials 2, pp.105117, 1993.

[2] R. Milazzo, M. Linser, D. Scarpa, A. Carnera, A. Andrighetto, E. Napolitani, "Indiffusion of oxygen in germanium induced by pulsed laser melting", Materials Science in Semiconductor Processing, vol. 88, pp.93-96, 2018.

[3] K. Huet, F. Mazzamuto, T. Tabata, I. Toqué-Tresonne, and Y. Mori, "Doping of semiconductor devices by laser thermal annealing", Materials Science in Semiconductor Processing, vol. 62, pp.92-102, 2017.

[4] F. Liu, H. Wong, K. Ang, M. Zhu, X. Wang, D.M. Lai, P. Lim and Y. Yeo, "Laser annealing of amorphous germanium on silicon-germanium source/drain for strain and performance enhancement in pMOSFETs", IEEE Electron Device Letters, vol. 29 (8), pp. 885-888, 2008.

[5] O. Gluschenkov, et al, "External resistance reduction by nanosecond laser anneal in $\mathrm{Si} / \mathrm{SiGe} \mathrm{CMOS}$ technology", in Proc. IEEE Int. Electron Devices Meeting (IEDM), 2018.

[6] L Dagault et al, "Impact of UV nanosecond laser annealing on composition and strain of undoped $\mathrm{Si}_{0.8} \mathrm{Ge}_{0.2}$ epitaxial layers", ECS Journal of Solid State Science and Technology Vol. 8, (3), pp202-208, 2019.

[7] L.Dagault et al, "Investigation of recrystallization and stress relaxation in nanosecond laser annealed Si1-xGex/Si epilayers" Applied Surface Science vol. 527, (2020) 146752.

[8] S.F. Lombardo et al, "Theoretical study of the laser annealing process in FINFET structures", Applied Surface Science vol. 467-468, pp. 666-672, 2019.

[9] G. Fisicaro, A. La Magna, G. Picitto and V. Privitera, "Laser annealing of SiGe and Ge based devices", Microelectronic Engineering vol. 88, pp. 488491, 2011.

[10] K. Huet et al, "Pulsed laser annealing for advanced technology nodes: Modeling and calibration”, Applied Surface Science vol. 505, 2020, 144470. 